\title{
Performance measurement of the relationship between students' learning with lecturers' characteristics as supervisors based on fuzzy-based assessment
}

\author{
Mulyanto a,1, Bedi Suprapty a,2, Arief Bramanto Wicaksono Putra a,3,", Achmad Fanany Onnilita Gaffar a,4 \\ ${ }^{a}$ Department of Information Technology, Politeknik Negeri Samarinda, East Kalimantan, Indonesia \\ 1 yanto1294@gmail.com; ${ }^{2}$ bedirheody@gmail.com; ${ }^{3}$ ariefbram@gmail.com*; 4 onnygaffar212@gmail.com \\ * Corresponding Author
}

Received 19 July 2020; Accepted 30 January 2021; Published 24 February 2021

\begin{abstract}
In addition to the focus of research selected as a Final Project material, the selection of lecturers as student's supervisor becomes very important. The lecturer's competence related to the focus of student research and the supervising style of lecturers is also very influential on the final results. Measurement of style appropriateness between students' learning styles and supervising lecturers' styles can benchmark the quality of the final project's implementation, especially higher education institutions. This study has applied fuzzy-based assessment to build objective perceptions of students' learning characteristics and lecturers' characteristics (Visual (V), Auditory (A), Kinesthetic (K)) as supervisors through questionnaire processing that has designed in such away. Hence, it is suitable for this study. The measuring technique of the percentage of overlapping areas under the curves and the correlation test between a pair of curves have been used as performance measurement metrics. In general, the study results indicate a significant level of coverage adequacy for all research variables regarding existing conditions. It means that the process of Final Project activities in terms of students' and lecturers' learning characteristics as supervisors and their distribution is at a reasonable level (88.38\%). It has also been shown by the results of the correlation test of the appropriateness of choice, both supervisors selected by students $(0.8657)$ and students chosen by lecturers $(0.9897)$ who are at a very significant level of similarity. Correlation tests conducted for similarities between students' and lecturers' learning characteristics as supervisors show almost no significant correlation between them (0.4064).
\end{abstract}

\section{Introduction}

The Final Project is the final estuary for students during their education in a higher education institution. In addition to the selected focus of research as a Final Project material, the selection of lecturers as their supervisors becomes very important. Not only aspects of the competence of lecturers are related to their research's focus, but the lecturer's supervising style is also very influential on the final result. Commonly, the supervising style of the lecturer is directly related to the teaching style in the classroom. As well as students, their learning style will be the primary resource in completing their Final Project. Measurement of the style's appropriateness, between students' learning styles and the supervising style of lecturers, can be a benchmark of the quality of the implementation of the Final Project in particular higher education institutions.

Knowledge of student characteristics is quite essential in the concept of learning technology. Knowledge of student characteristics will affect whether or not the lecturer is appropriate for delivering the chosen learning message. In principle, there is no one strategy for delivering the best learning messages unless the strategy is appropriate and appropriate to student learning characteristics. One of the characteristics of students that need to be identified is students' learning styles. The quality of the learning process in lectures will increase if the lecturer's teaching message delivery strategy is under students' 
learning styles. The success of the teaching and learning process can also be measured by students who take part in learning activities, including the level of Understanding, mastery of the material, and measuring student achievement. It is also applied when the lecturer performs the task as a supervisor of the Final Project.

The learning styles are defined as students' learning behaviors, such as reading, seeing, listening, and trying to imitate [1]. There is a fundamental difference between learning styles and cognitive styles. Compared to cognitive styles, learning styles are more visible in terms of the strategies students use to deal with learning. Compared to learning styles, cognitive style places more emphasis on the naturalness of the individual, habits, and ways of absorbing, processing, and maintaining new information and skills that are preferred [2].

One of the problems faced by lecturers is that the teaching methods used do not match student learning styles' characteristics. This condition will also significantly affect when the lecturer acts as a supervisor of students with individual learning styles. Many learning methods can be applied to students. Problembased learning emphasizes student activity in finding solutions to problems. In applying this method, the lecturer allows students to determine the topic of the problem. Inquiry learning is a teaching technique in which lecturers involve students in the learning process through the use of questions, problem-based learning activities, and critical thinking. Therefore, students are involved mentally and physically to solve the lecturer's problems [3]. Quantum learning strategies are usually applied to motivate students to be involved in the learning environment. This strategy combines each component of emotional learning with students so that the relationship between the lecturer and students' emotional condition can create a more meaningful and permanent learning environment [4]. Various innovative teaching methods are now widely used. Hybrid teaching is combining face-to-face teaching with the use of e-learning facilities. Technology and multimedia, such as smart gadgets for different tasks such as teaching, designing question papers, student assessment, and feedback, have also been widely used. Innovative teaching and learning methodologies such as short lectures, simulations, roleplaying, portfolio development, and problem-based learning (PBL) are very useful in overcoming the rapid development of technological advancements and workplace development that needed in the future [4].

One of the most popular and most widely used learning style models is the VAK (Visual, Auditory, Kinesthetic) model proposed by Neil Fleming [5]. Visual style - prefers calmness and order around them if it is difficult to maintain concentration. Visual students best remember what they see in the text, video, graphics, and the like. They like to make handwritten notes and are not disturbed by surrounding sounds during the study. Auditory style - likes learning by listening to lectures, reading aloud, and leading discussions. They have problems with reading graphical forms and the like. They prefer to talk about action rather than watch it. They have the ease of learning languages. They need silence to study. Kinesthetic style - feeling the best in moving, like working in groups, and quickly tired when listening to lectures. They need a break between study sessions. Any movement around them might disturb them [6].

There are two models of approaches to detect learning style models: (1). Conventional, using a questionnaire to find learning styles; (2). automatic: (a). data-driven, using data-driven methods that implement $\mathrm{AI}$ in the detection process; (b). literature-based, using student learning outcomes of available teaching materials. The prior knowledge approaches have been used to build a VARK learning style detection model. This approach is carried out to prove the relationship between learning styles with prior knowledge and achieve more accurate detection results [7].

Furthermore, the prior knowledge approach involves three stages: producing prior knowledge and determining the level of knowledge and prediction of learning styles. Knowledge-based levels have also been used to detect student learning style models [8]. Detection of learning style models based on student behavior during their interactions with learning objects and mapping rules to infer learning styles for the Felder-Silverman Learning Style Model has also been carried out [9]. Artificial Neural Networks have also 
been used to build learning style detection models, which begin with the process of generating prior knowledge using the Latent Semantic Indexing (LSI) method [10]. Other methods that have also been used to detect learning style models are such as the use of tree-augmented Bayes [11], and hybrid methods which are a combination of literature-based detection and automatic detection [12].

In addition to the learning style detection activity, there are many methods and approaches used to measure student learning styles' performance. The various performance measurement methods used must be related to the stated measurement objectives. ANOVA has been used to measure students' awareness of learning styles and academic performance based on their GPA [13]. A study of the Relationship between Kolb Learning Style, Gender, and Student Learning has conducted. The relationship levels had shown using regression techniques [14]. A statistical approach has also been used to measure the relationship between learning styles, academic performance, and teaching evaluation results [15]_[17].

This study uses data obtained from the Information Technology Department, Samarinda State Polytechnic. In this institution, students have the freedom to choose lecturers as their supervisors. Likewise, lecturers also have the right to accept or reject student proposals related to their position as prospective supervisors. Students' learning styles become their primary resources in working on Final Projects, including in consulting activities with their respective supervisors. The teaching style of the lecturers is assumed to represent their supervising style to the students they supervise. This study observes students' learning styles and the teaching styles of lecturers considered as research variables.

This study measures the relationship between the two characteristic models of the observations and the distribution proportion of selected students/lecturers for each characteristic model. Fuzzy-based assessment is used to determine students' learning styles from the results of data observations via a questionnaire model — aggregation of all measurements considered as total performance.

\section{Method}

\subsection{Learning stages and methods}

In general, there are four levels of human learning positions, namely: (1). Unconscious incompetence; (2). Conscious incompetence; (3). Conscious competence; (4). Unconscious competence. The transition between levels of learning positions, as mentioned above, requires the following phases of learning:

1) Knowledge Acquisition is a process of transition from the level of unconscious incompetence to conscious incompetence. The process in this stage is also called Memorizing (absorbing knowledge

2) Knowledge Transformation is a process of transition from the level of conscious incompetence to conscious competence. The process in this stage is also called Understanding.

3) Knowledge Evaluation is a process of transition from the level of conscious competence to unconscious competence. The process in this stage is also called Comprehension.

The learning method is defined as a method used to implement plans that have been prepared in the form of real and practical activities to achieve learning objectives. Several learning methods can be used related to the learning phases and student learning styles, as follows:

1) Multimedia-based teaching is the teaching method that applies multimedia devices in the delivery of subject matter information.

2) Lecture-based teaching is a teaching method used to convey information or describe an issue orally.

3) Demonstration-based teaching is a method of presenting lessons by demonstrating and demonstrating to students about a particular process, situation, or object, whether actual or just an imitation.

4) Problem-Solving based teaching is a method of thinking that can use other methods, starting with finding data until concluding. 
5) Discussion-based teaching is a learning method that exposes students to a problem to be solved through a discussion forum.

6) Exercise-based teaching is generally used to acquire dexterity or skill from what has been learned.

7) Project/Case Study-based teaching is a way of presenting lessons that start with a problem, then discussed various related aspects so that the solution is overall and meaningful.

8) Question and answer-based teaching is a teaching method that allows direct communication that is twoway traffic because, at the same time, there is a dialogue between the teacher and students.

9) Experiment-based teaching is a way of presenting lessons, where students conduct experiments by experiencing and proving themselves something they have learned.

From the previous description, it can be summarized as shown in Table 1. The choice of teaching methods by the lecturer can be analogous to the characteristics of the teaching style of the lecturer, represented by the characteristics $V, A$, and $K$.

\subsection{The Proposed Method}

This study applies Fuzzy Logic's concept in assessing the performance of the relationship between the learning characteristics of students with the characteristics of lecturers as supervisors. In general, the proposed method is shown in Fig. 1. All the data needed obtaining by distributing questionnaires to respondents (students) according to the type of data. The questionnaire was made to capture data of respondents under research needs.

Table 1. Teaching method based on the learning phase for each type of learning style characteristics

\begin{tabular}{cccc}
\hline Learning phase & Visual (V) & Auditory (A) & Kinesthetic (K) \\
\hline Memorizing & Multimedia & Lecture & Demonstration \\
\hline Understanding & Problem-solving & question and answer & Practice \\
\hline Comprehension & Case study & Discussion & Experiment \\
\hline
\end{tabular}

\subsection{Questionnaire Design}

There are two types of questionnaires: (1). Questionnaire to capture data on learning characteristics of students; (2). Questionnaire to capture data on the characteristics of the lecturer as a supervisor. Students are the respondents of both types of questionnaires. In principle, the two types of the questionnaire to map the Visual characteristics $(V)$, Auditory $(A)$, and Kinesthetic $(K)$ of both students and lecturers. Students with visual characteristics learn through what they see. Students with auditory characteristics learn through what they hear. In comparison, students with kinesthetic characteristics learn through motion and touch. Although each person learns with these three modalities, most people are more inclined towards one of the three. The attributes of each student learning characteristic shown in Table 2.

The lecturer's characteristics as a supervisor determined by choice of teaching methods at each student learning stage (memorizing, Understanding, Comprehension). These characteristics are based on students' perceptions while attending teaching/guidance from lecturers. The types of teaching methods according to the stages of the learning process for each $\mathrm{V}-\mathrm{A}-\mathrm{K}$ characteristic shown in Table 1 . All questions in each type of questionnaire were made by referring to Table 1 and Table 2. The assessment of each question in the questionnaire is based on a qualitative rating: never, infrequently, and frequently - each rating is given a weight of 0,1 , and 2, respectively. For example, the completed questionnaire is shown in Table 3 and Table 4. 


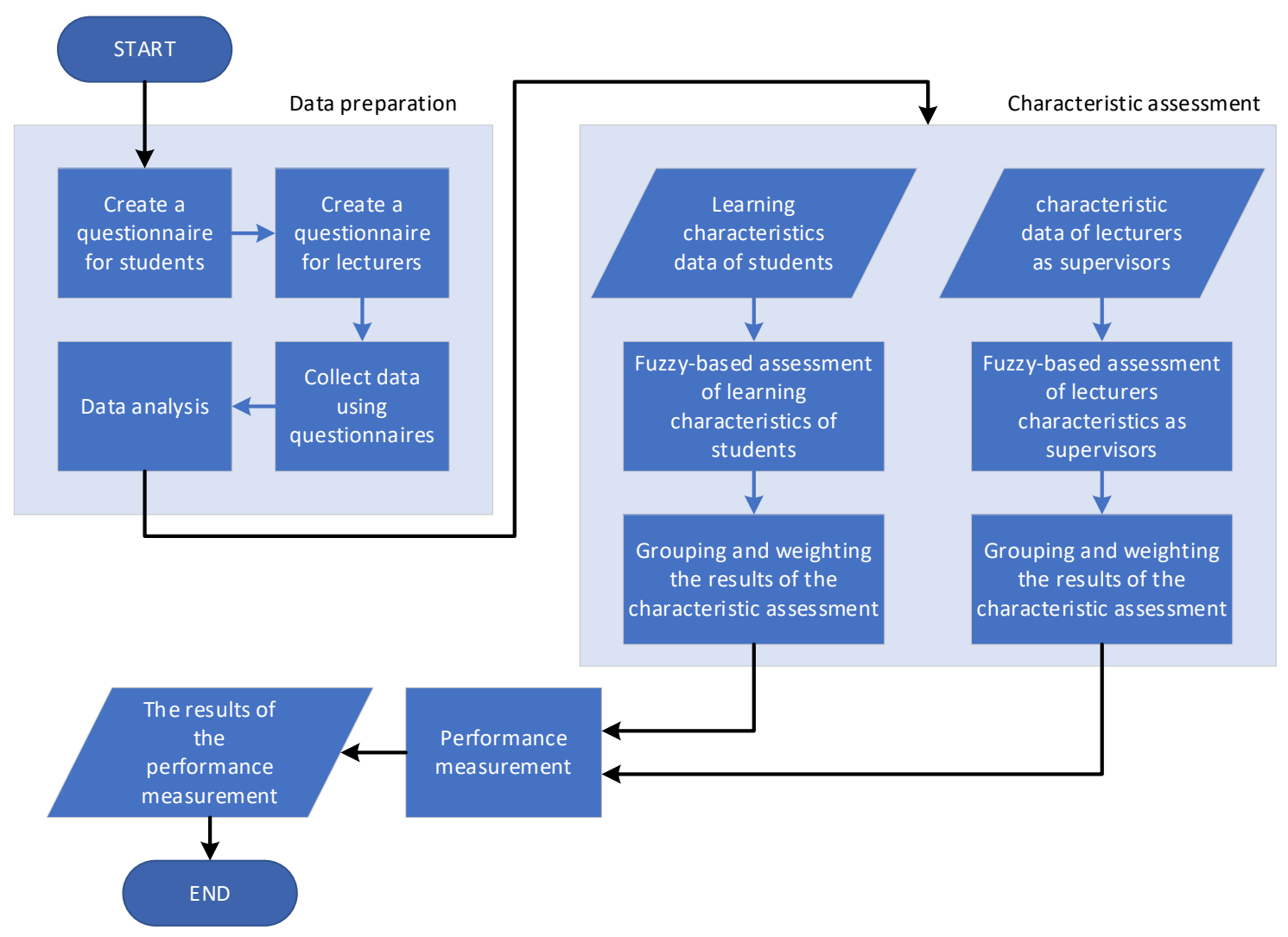

Fig. 1. The proposed method

Table 2. The attributes of each student learning characteristic

\begin{tabular}{cccc}
\hline No. & Visual $(V)$ & Auditory $(A)$ & Kinesthetic $(K)$ \\
\hline 1 & Talk quickly & Speak with a patterned rhythm & Speak slowly. \\
\hline 2 & $\begin{array}{c}\text { Often know what will be said but } \\
\text { have difficulty choosing words. }\end{array}$ & $\begin{array}{c}\text { Fluent speaker. Like to talk, like to } \\
\text { discuss, and explain something at } \\
\text { length. }\end{array}$ & $\begin{array}{c}\text { Feeling difficult in writing } \\
\text { but good in story telling. }\end{array}$ \\
\hline 3 & $\begin{array}{c}\text { It's easier to remember what is } \\
\text { seen than what is heard. }\end{array}$ & It's easier to remember what was heard. & Study with practice. \\
\hline 4 & Likes to read. & Likes to read aloud and listen. & $\begin{array}{c}\text { Reflect action with body } \\
\text { movements while reading. }\end{array}$ \\
\hline 5 & $\begin{array}{c}\text { Usually not disturbed by the } \\
\text { commotion. }\end{array}$ & Easily disturbed by noise. & $\begin{array}{c}\text { Not easily disturbed by } \\
\text { noise. }\end{array}$ \\
\hline
\end{tabular}

Table 3. An example of a questionnaire to acquire Visual characteristics of student learning

\begin{tabular}{|c|c|c|c|c|}
\hline No. & Questions & frequently & infrequently & never \\
\hline 1. & In speaking, you use fast rhythm & $\mathrm{X}$ & & \\
\hline 2. & $\begin{array}{l}\text { You have trouble choosing words to convey what you } \\
\text { know }\end{array}$ & & $\mathrm{X}$ & \\
\hline 3. & You can remember what you saw & $\mathrm{X}$ & & \\
\hline 4. & You like to read under any conditions & $\mathrm{X}$ & & \\
\hline 5. & $\begin{array}{l}\text { In doing something, you are not easily disturbed by the } \\
\text { surrounding environment }\end{array}$ & & & $\mathrm{X}$ \\
\hline & Sub total & 6 & 1 & 0 \\
\hline & Total & & 7 & \\
\hline
\end{tabular}


Table 4. An example of a questionnaire to acquire Visual characteristics of lecturer as a supervisor

\begin{tabular}{|c|c|c|c|c|}
\hline \multicolumn{5}{|c|}{ Selected Supervisor number : 1} \\
\hline No. & Questions & frequently & infrequently & never \\
\hline 1. & $\begin{array}{l}\text { Your supervisor prefers to use multimedia-based teaching } \\
\text { methods to convey new knowledge to you. }\end{array}$ & & $\mathrm{X}$ & \\
\hline 2. & $\begin{array}{c}\text { Your supervisor prefers to use teaching methods based on } \\
\text { problem solving to deepen your knowledge. }\end{array}$ & & $\mathrm{X}$ & \\
\hline 3. & $\begin{array}{c}\text { Your supervisor prefers to use case study-based teaching } \\
\text { methods to develop your knowledge. }\end{array}$ & $\mathrm{X}$ & & \\
\hline & Sub total & 2 & 2 & 0 \\
\hline & Total & & 4 & \\
\hline
\end{tabular}

\subsection{Processing questionnaire results}

All completed questionnaires were processed in such a way as to obtain groupings based on the type of characteristics. Examples of formats of completed questionnaire processing results are shown in Table 5 and Table 6 , while Table 6 is obtained after the questionnaire results' recapitulation process. Both of the processed data will be used as input for the fuzzy-based assessment process.

Table 5. An example format of completed questionnaire processing results for students' learning characteristics observation

\begin{tabular}{ccccc}
\hline Respondent no. & Visual & Auditory & Kinesthetic & Selected supervisor number \\
\hline 1. & 1 & 7 & 3 & 15 \\
\hline 2. & 4 & 4 & 3 & 19 \\
\hline 3. & 1 & 0 & 4 & 3 \\
\hline 4. & $\ldots$ & $\ldots$ & $\ldots$ & $\ldots$ \\
\hline
\end{tabular}

Table 6. An example format of completed questionnaire processing results for students' learning characteristics observation

\begin{tabular}{ccccc}
\hline Selected supervisor number & Visual & Auditory & Kinesthetic & Number of selected students \\
\hline 1. & 0 & 9 & 8 & 2 \\
\hline 2. & 9 & 4 & 8 & 8 \\
\hline 3. & 6 & 3 & 7 & 7 \\
\hline 4. & $\ldots$ & $\ldots$ & $\ldots$ & $\ldots$ \\
\hline
\end{tabular}

\subsection{Fuzzy-based assessment}

There will be three sub-data groups for each data processing result, namely the Visual, Auditory, and Kinesthetic Groups. The assessment of characteristics based on the three sub-data groups' aggregation using the Fuzzy Inference System (FIS). The FIS output is a type of character for each data record. The FIS structure created is used to assess the final characteristics of the two categories of characteristics to be evaluated (the characteristics of student learning and lecturers' characteristics as supervisors) as shown in Fig. 2 [18].

There are three inputs: (1). Visual $(V)$; (2). Auditory $(A)$; (3). Kinesthetic $(K)$. Each input needs to be fuzzified using a fuzzy set. This study uses three linguistic values for each fuzzy set (Low(1), Medium(2), High(3))Each linguistic value is represented using the Triangular Membership Function (MF) [19], as shown in Fig. 3. The universe of discourse from fuzzy set input is determined based on the questionnaire's minimum and maximum weight. Because each questionnaire consists of five questions, the maximum weight value is $2 \times 5=10$, so the universe of discourse is within the range: $\{0 \ldots$ 10\}. The fuzzy output set is planned to have five linguistic values $(K, A K, A, V A, V)$, taking into consideration the overlap between characteristics. $A K$ is the overlapping characteristic between $A$ and $K$, so is $V A$. The membership function used is the same as the fuzzy input set. The universe of discourse is set to range: $\{0 \ldots 1\}$. The fuzzy set of inputs and outputs shown in Fig. 4. 
The FIS uses a set of rules to infer all fuzzified inputs to produce its output. The first step is input fuzzification, i.e., determine their degree of membership in the appropriate fuzzy set via the membership function. Inputs that are already in the degree of membership of the appropriate fuzzy set are called fuzzy numbers. Fuzzy numbers are used in the application of fuzzy rules. Each rule consists of antecedents and consequents. $A N D(\mathrm{~min})$ fuzzy operator for the Mamdani model commonly used to antecedents that have more than one part. The results of the application of $A N D$ fuzzy operators are single numbers that are used to implicate the consequent parts, which also using the $A N D$ operators. The process of implication on all fuzzy rules produces several fuzzy output sets. All fuzzy output sets from the implication process are then aggregated by using $O R(\max )$ operator to produce a single fuzzy set. Finally, this fuzzy set is defuzzified to produce a crisp number as the final FIS output. One of the most popular defuzzification methods is $C O A$ (Center of Area) which is stated by:

$$
x_{c}=\frac{\sum_{i=1}^{n} x_{i} \cdot \mu\left(x_{i}\right)}{\sum_{i=1}^{n} \mu\left(x_{i}\right)}
$$

where $x_{c}$ is the COA value, $x_{i}$ is the $x$ value of $\mathrm{i}$-th index, $\mu\left(x_{i}\right)$ is the degree of membership of $x_{i}$, and $\mathrm{n}$ is the number of $\left(x_{i}, \mu\left(x_{i}\right)\right)$ pairs in the curve.

Suppose there are two inputs $A$ and $B$ and one output. Both $A, B$, and $C$ mapped into fuzzy sets that have three linguistic values (Low, Medium, High), as shown in Fig. 5. If $A(x)=20$ and $B(x)=$ 65 for the rule:

antecedent

consequent

\section{IF A is Low AND B is Medium THEN C is Medium}

The FIS output in crisp numbers is used to map the final characteristics regarding the value intervals shown in Fig. 8. Suppose the FIS output 0.45 is in the interval so that it classified as

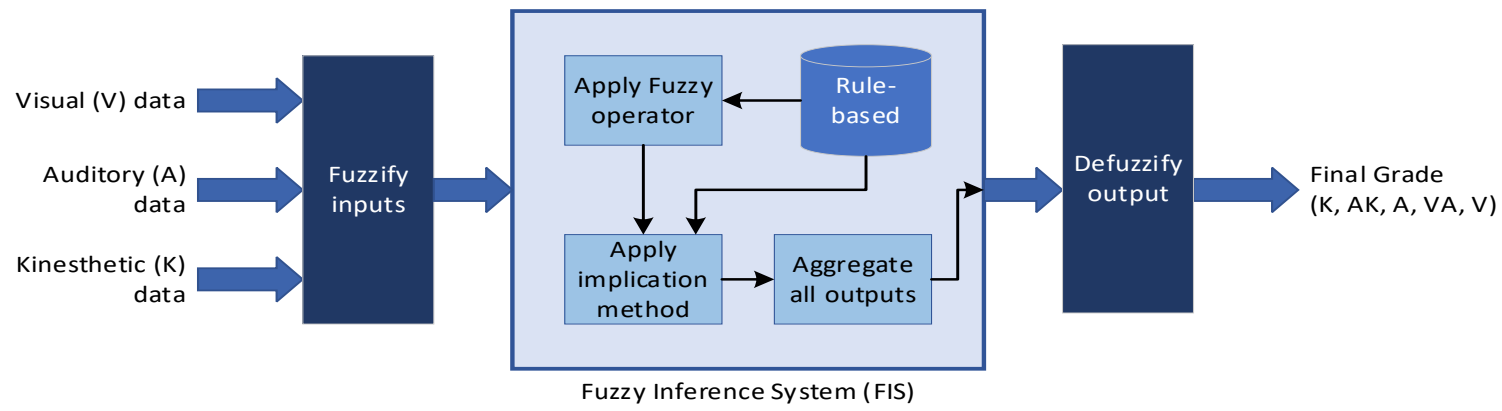

Fig. 2. Fuzzy Inference System

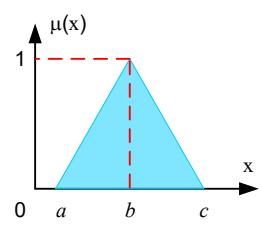

$$
\mu(x)=\operatorname{trimf}(x, a, b, c)=\left\{\begin{array}{cc}
0 & x \leq a, x \geq c \\
\frac{x-a}{b-a} & a \leq x \leq b \\
\frac{c-x}{c-b} & b \leq x \leq c
\end{array}\right.
$$

Fig. 3. Triangular MF

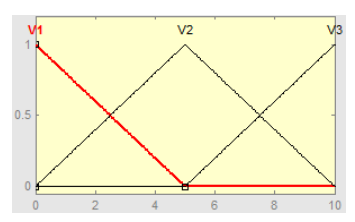

(a). The fuzzy set $V$

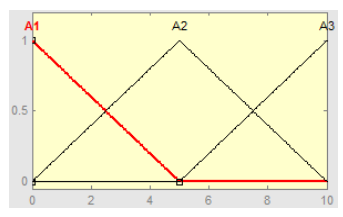

(b). The fuzzy set $A$

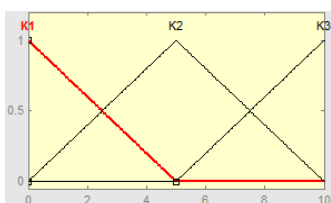

(c). The fuzzy set $K$

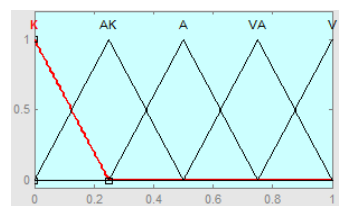

(d). The fuzzy set of the final characteristic

Fig. 4. The fuzzy set of inputs and outputs 


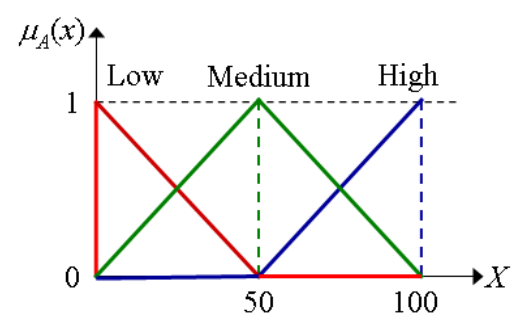

Fig. 5. The fuzzy set

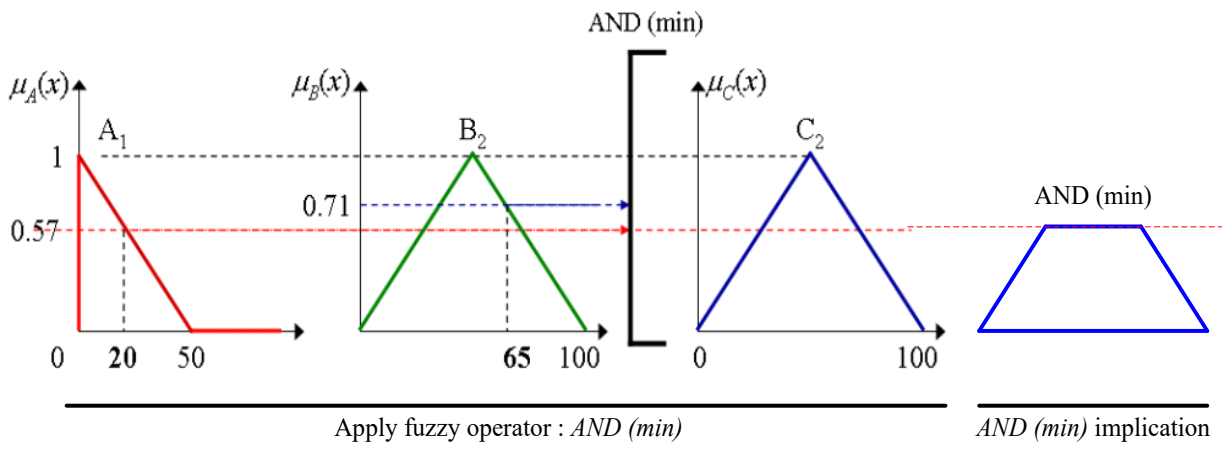

Fig. 6. Application of $A N D$ fuzzy operators and $A N D$ implications

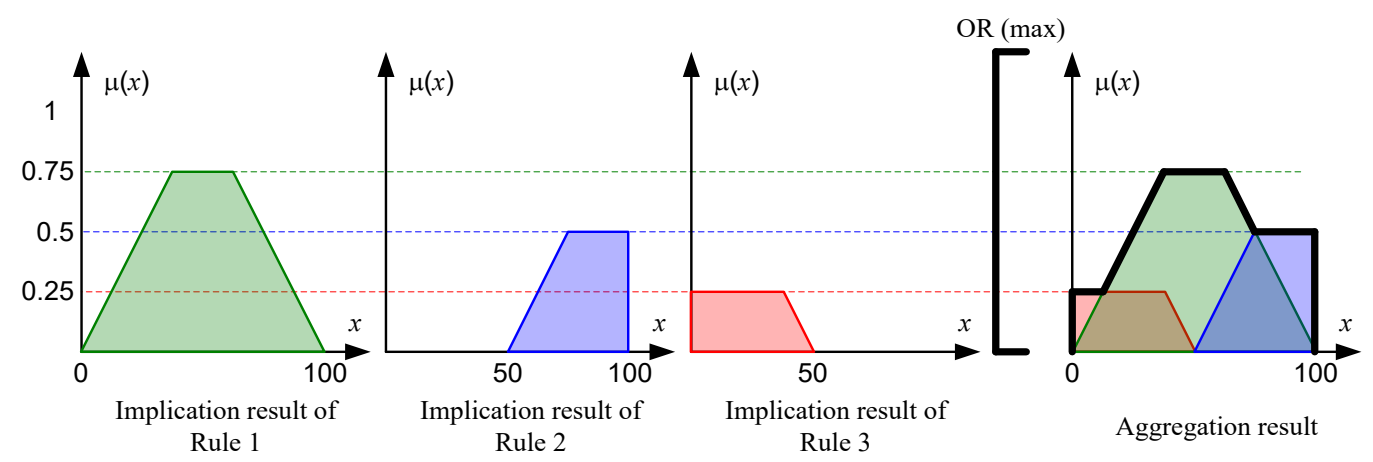

Fig. 7. An example of the aggregation process using the $O R$ operator

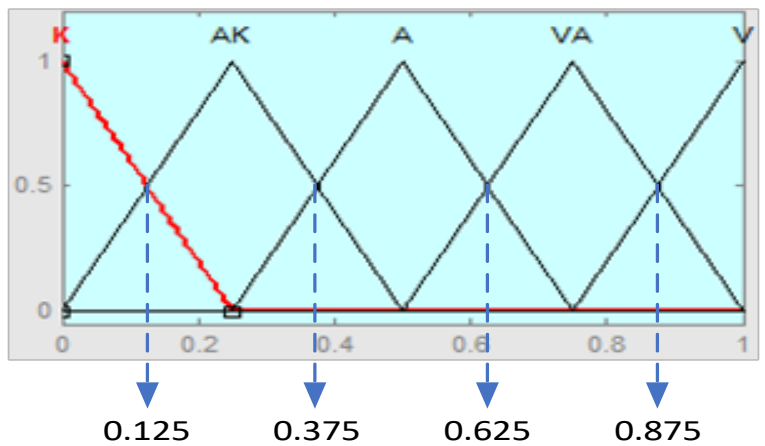

Fig. 8. The value intervals of final characteristics

The set of fuzzy rules planned to be able to map all inputs into grades $K, A K, A, V A, V$ are as follows:

1. If $V$ is Low and $A$ is Low and $K$ is High then Grade is $K$

2. If $V$ is Low and $A$ is Medium and $K$ is High then Grade is $K$

3. If $V$ is Medium and $A$ is Low and $K$ is High then Grade is $K$

4. If $V$ is Medium and $A$ is Medium and $K$ is High then Grade is $K$ 
5. If $V$ is Low and $A$ is Low and $K$ is Medium then Grade is $K$

6. If $V$ is Low and $A$ is High and $K$ is High then Grade is $A K$

7. If $V$ is Medium and $A$ is High and $K$ is High then Grade is $A K$

8. If $V$ is Low and $A$ is Medium and $K$ is Medium then Grade is $A K$

9. If $V$ is Medium and $A$ is High and $K$ is Medium then Grade is $A$

10. If $V$ is Low and $A$ is High and $K$ is Medium then Grade is $A$

11. If $V$ is Medium and $A$ is High and $K$ is Low then Grade is $A$

12. If $V$ is Low and $A$ is High and $K$ is Low then Grade is $A$

13. If $V$ is Low and $A$ is Medium and $K$ is Low then Grade is $A$

14. If $V$ is High and $A$ is High and $K$ is Medium then Grade is $V A$

15. If $V$ is High and $A$ is High and $K$ is Low then Grade is $V A$

16. If $V$ is Medium and $A$ is Medium and $K$ is Low then Grade is $V A$

17. If $V$ is High and $A$ is Medium and $K$ is Medium then Grade is $V$

18. If $V$ is High and $A$ is Low and $K$ is Medium then Grade is $V$

19. If $V$ is High and $A$ is Medium and $K$ is Low then Grade is $V$

20. If $V$ is High and $A$ is Low and $K$ is Low then Grade is $V$

21. If $V$ is Medium and $A$ is Low and $K$ is Low then Grade is $V$

The final result of this stage is the mapping results of characteristics $(K, A K, A, V A, V)$, both for students and lecturers, referring to Table 5 and Table 6 . This stage is considered as a stage of grouping respondents into clusters $K, A K, A, V A$ and . Each cluster will consist of several respondents.

\subsection{Grouping and weighting the results of the characteristic assessment}

After the fuzzy-based assessment phase, each type of processed data is grouped based on its final characteristics. Examples format of completed questionnaire processing results are shown in Table 7 and Table 8.

Table 7. An example format of completed questionnaire processing results for students' learning characteristics observation

\begin{tabular}{ccc}
\hline Type of characteristic & Number of students & Number of selected supervisors \\
\hline $1(K)$ & 9 & 2 \\
\hline $2(A K)$ & 29 & 2 \\
\hline $3(A)$ & 30 & 2 \\
\hline $4(V A)$ & 23 & 4 \\
\hline $5(V)$ & 9 & 2 \\
\hline
\end{tabular}

Table 8. An example format of completed questionnaire processing results for students' learning characteristics observation

\begin{tabular}{ccc}
\hline Type of characteristic & Number of lecturers & Number of selected students \\
\hline $1(K)$ & 3 & 31 \\
\hline $2(A K)$ & 4 & 37 \\
\hline $3(A)$ & 2 & 23 \\
\hline $4(V A)$ & 1 & 9 \\
\hline $5(V)$ & 0 & 0 \\
\hline
\end{tabular}


Normalization in each column of data is carried out to obtain its weight. Suppose $X$ is a data set that represents data from Table 7, and $Y$ represents data from Table 8. Data normalization is expressed by:

$$
W_{X}(i, j)=\frac{X(i, j)}{\sum_{i=1}^{5} X(i, j)} \quad W_{Y}(i, j)=\frac{Y(i, j)}{\sum_{i=1}^{5} Y(i, j)} \quad j=1,2
$$

$W_{X}(:, 1)$ is the weight of the characteristics of student learning for each type, while $W_{X}(:, 2)$ is the weight of the supervisor distribution chosen for each type. $W_{Y}(:, 1)$ is the weight of the characteristics of the lecturer as a supervisor for each type, while $W_{Y}(:, 2)$ is the weight of the student distribution who supervised for each type.

This stage produces four pairs of data, which will be compared later. The goals of comparing each pair of data are as follows:

1. A comparison of data pairs $\left(W_{X}(:, 1), W_{X}(:, 2)\right)$ is to measure the appropriateness of selected supervisors by students towards the characteristics of their learning.

2. A comparison of data pairs $\left(W_{Y}(:, 1), W_{Y}(:, 2)\right)$ is to measure the appropriateness of selected students by lecturers towards their characteristics as a supervisor.

3. A comparison of data pairs $\left(W_{X}(:, 1), W_{Y}(:, 1)\right)$ is to measure the similarity of the characteristics of students and lecturers.

4. A comparison of data pairs $\left(W_{X}(:, 2), W_{Y}(:, 2)\right)$ is to measure the appropriateness of selected supervisor $\&$ student distributions towards their characteristics.

\subsection{Performance measurement}

This section briefly describes the performance evaluation results. In principle, the performance measurement is carried out by measuring the difference between each pair of data. This measurement aims to determine how close the relationship between the two curves in each pair of data. Some performance metrics used are as follows:

1. Correlation coefficient.

Suppose there are two curves, $X$ and, the correlation coefficient between those two curves are expressed by:

$$
r_{X, Z}=\frac{\sum_{i=1}^{n}\left(X_{i}-\bar{X}\right) \cdot\left(Z_{i}-\bar{Z}\right)}{\sqrt{\left(\sum_{i=1}^{n}\left(X_{i}-\bar{X}\right)^{2}\right) \cdot\left(\sum_{i=1}^{n}\left(Z_{i}-\bar{Z}\right)^{2}\right)}}
$$

where $\bar{X}$ is the mean of $X$ and $\bar{Z}$ is the mean of $Z$. If $r_{X, Z}$ close to \pm 1 , the two curves are considered similar, and vice versa.

2. Percentage of the overlapping area under the curve

Suppose there is a $Y$ curve such that $Y=f(X)$ where $X=x_{1} \ldots x_{n}$ The area under the $\mathrm{Z}$ curve expressed by:

$$
A_{Y}=\sum_{i=1}^{n} f\left(x_{i}\right) \cdot x_{i}
$$

Suppose there are curves $Y$ and $Z$ such that $Y=f_{Y}(X)$ and $Z=f_{Z}(X)$ where $X=x_{1} \ldots x_{n}$. The overlapping area under the $Y$ and $Z$ curves expressed by:

$$
A_{d i f}=\sum_{i=1}^{n} \min \left(f_{Y}\left(x_{i}\right), f_{Z}\left(x_{i}\right)\right) \cdot x_{i}
$$

Percentage of the overlapping area under the curve expressed by: 


$$
\% A_{d i f, Y}=\frac{A_{d i f}}{A_{Y}} \times 100 \% \quad \% A_{d i f, Z}=\frac{A_{d i f}}{A_{Z}} \times 100 \%
$$

This metric is used to measure how many parts of the original curve cover the existing conditions.

\subsection{Datasets}

This study uses data obtained from the implementation of the Final Project in the Department of Information Technology - Politeknik Negeri Samarinda in 2019. Data downloaded from the Final Project Monitoring System created by the Final Project Team, then processed in such a way and graphically presented in Fig. 9 and Fig. 10. The number of students as respondents is 150 people, classified as students who carry out the Final Project. This number is the total number of students from Computer Engineering, Computer Science, and Computer Science \& Multimedia Study Programs. The number of lecturers as supervisors is 23 people.

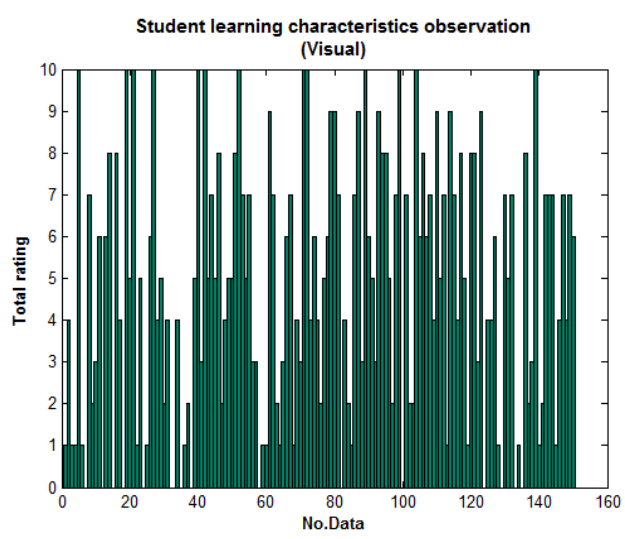

(a). Visual characteristic

Student learning characteristics observation

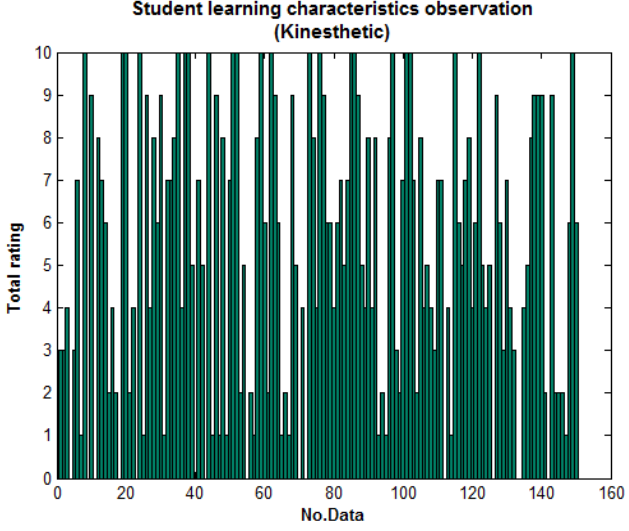

(c). Kinesthetic characteristic

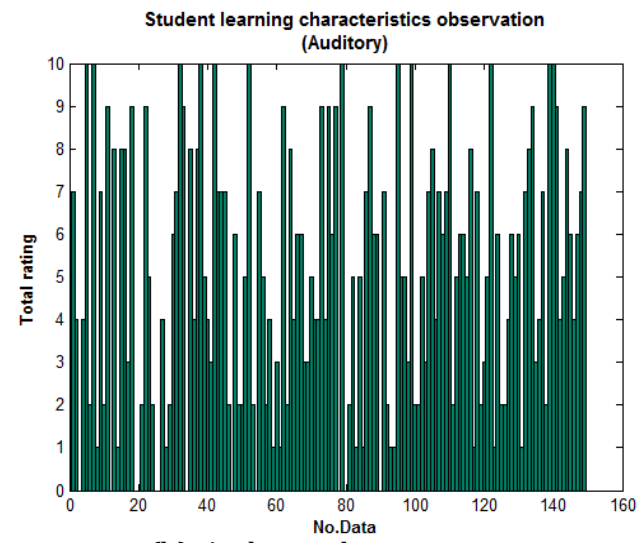

(b). Auditory characteristic

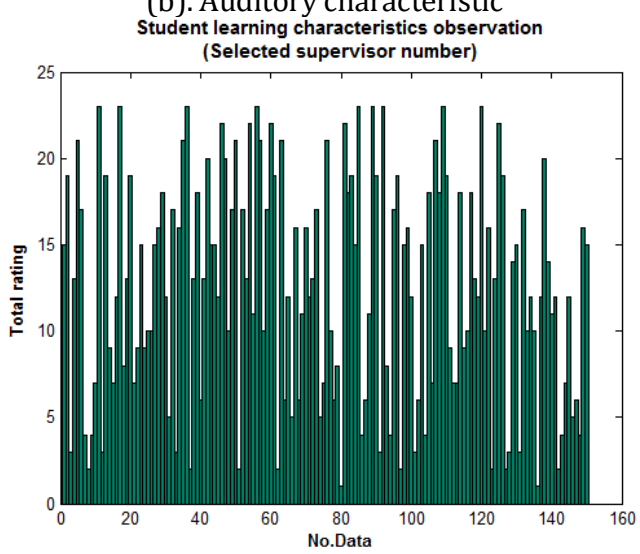

(d). Selected supervisor number

Fig. 9. Data on the observation results of students' learning characteristics

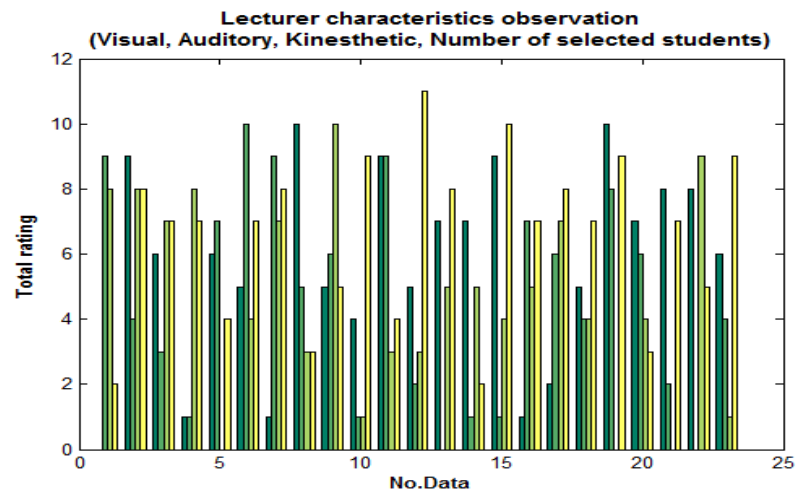

Fig. 10. Data on the observation results of lecturer characteristics 


\section{Results and Discussion}

In this study, all data processing is carried out under programming built using MATLAB. Fuzzy-based assessment results of all completed questionnaires were graphically shown in Fig. 11. The results of the grouping and weighting phase are shown in Table 9 and Table 10. The results of comparing four data pairs that have shown in Table 9 and Table 10 were presented in Table 11, Table 12, and Table 13, and visualized in Fig. 12 and Fig. 13.

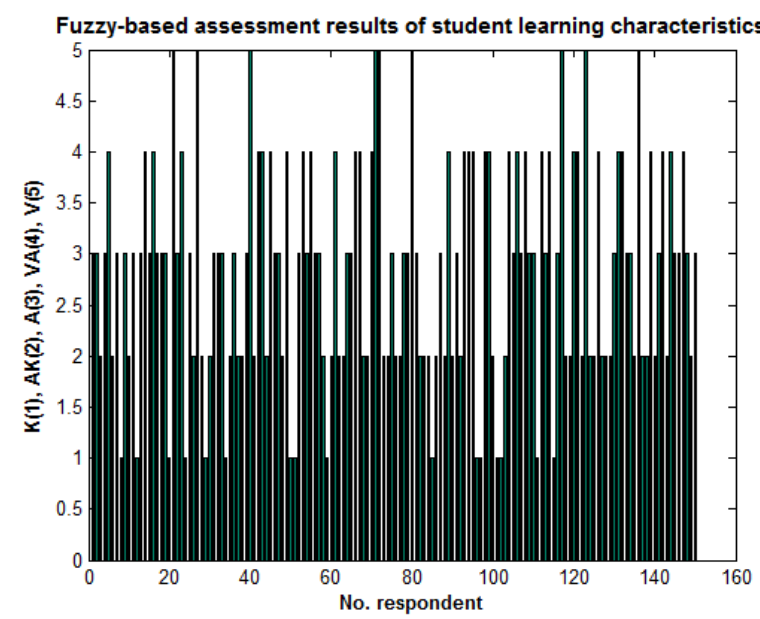

(a).

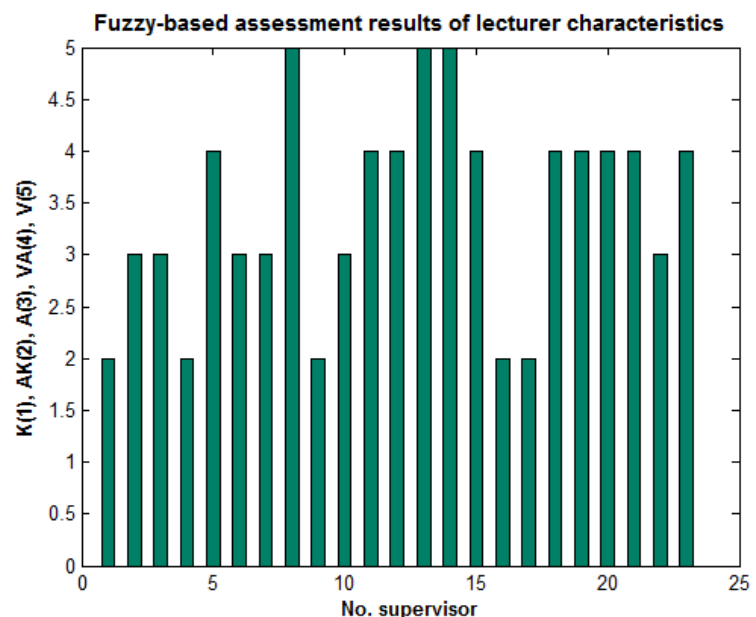

(b).

Fig. 11. Data on the observation results of lecturer characteristics

Table 9. The grouping and weighting result for students' learning characteristics $(X)$

\begin{tabular}{ccccc}
\hline $\begin{array}{c}\text { Type of } \\
\text { characteristic }\end{array}$ & $\begin{array}{c}\text { Number of } \\
\text { students } \\
(\boldsymbol{X}(:, \mathbf{1}))\end{array}$ & $\begin{array}{c}\text { Number of selected } \\
\text { supervisors } \\
(\boldsymbol{X}(:, \mathbf{2}))\end{array}$ & $\begin{array}{c}\text { The weight of the } \\
\text { number of students } \\
\left(\boldsymbol{W}_{\boldsymbol{X}}(:, \mathbf{1})\right)\end{array}$ & $\begin{array}{c}\text { The weight of the number } \\
\text { of selected supervisors } \\
\left(\boldsymbol{W}_{\boldsymbol{X}}(:, \mathbf{2})\right)\end{array}$ \\
\hline $1(K)$ & 16 & 10 & 0.1067 & 0.1299 \\
\hline $2(A K)$ & 45 & 20 & 0.3000 & 0.2597 \\
\hline $3(A)$ & 46 & 18 & 0.3067 & 0.2338 \\
\hline $4(V A)$ & 34 & 21 & 0.2267 & 0.2727 \\
\hline $5(V)$ & 9 & 8 & 0.0600 & 0.1039 \\
\hline
\end{tabular}

Table 10. The grouping and weighting result for lecturer characteristics $(Y)$

\begin{tabular}{ccccc}
\hline $\begin{array}{c}\text { Type of } \\
\text { characteristic }\end{array}$ & $\begin{array}{c}\text { Number of } \\
\text { lecturers } \\
(\boldsymbol{Y}(:, \mathbf{1}))\end{array}$ & $\begin{array}{c}\text { Number of selected } \\
\text { students } \\
(\boldsymbol{Y}(:, \mathbf{2}))\end{array}$ & $\begin{array}{c}\text { The weight of the } \\
\text { number of lecturers } \\
\left(\boldsymbol{W}_{\boldsymbol{Y}}(:, \mathbf{1})\right)\end{array}$ & $\begin{array}{c}\text { The weight of the number } \\
\text { of selected students } \\
\left(\boldsymbol{W}_{\boldsymbol{Y}}(:, \mathbf{2})\right)\end{array}$ \\
\hline $1(K)$ & 0 & 0 & 0.0000 & 0.0000 \\
\hline $2(A K)$ & 5 & 29 & 0.2174 & 0.1933 \\
\hline $3(A)$ & 6 & 44 & 0.2609 & 0.2933 \\
\hline $4(V A)$ & 9 & 64 & 0.3913 & 0.4267 \\
\hline $5(V)$ & 3 & 13 & 0.1304 & 0.0867 \\
\hline
\end{tabular}

Table 11. The area under curves calculation and their overlaps

\begin{tabular}{cccc}
\hline Types of curves & Area under the curve & \multicolumn{1}{c}{ Types of curve } & Area under the curve \\
\hline$W_{X}(:, 1)$ & 263.9810 & overlap $1\left(W_{X}(:, 1), W_{X}(:, 2)\right)$ & 240.1221 \\
\hline$W_{X}(:, 2)$ & 264.3939 & overlap $2\left(W_{Y}(:, 1), W_{Y}(:, 2)\right)$ & 299.9814 \\
\hline$W_{Y}(:, 1)$ & 309.0220 & overlap3 $\left(W_{X}(:, 1), W_{Y}(:, 1)\right)$ & 232.6570 \\
\hline$W_{Y}(:, 2)$ & 317.7724 & overlap $4\left(W_{X}(:, 2), W_{Y}(:, 2)\right)$ & 245.8547 \\
\hline
\end{tabular}


Table 12. Measurement of the percentage of overlapping area under the curves

\begin{tabular}{|c|c|c|c|}
\hline Pair of curves to be compared & $\begin{array}{c}\text { Types of the overlap } \\
\text { area }\end{array}$ & Description & $\begin{array}{c}\text { \%overlap } \\
\text { area }\end{array}$ \\
\hline \multirow{2}{*}{$\begin{array}{l}\text { Students' learning characteristics .vs. } \\
\text { their selected supervisors }\end{array}$} & $\%\left(\operatorname{overlap} 1 / W_{X}(:, 1)\right)$ & $\begin{array}{l}\text { The overlap between them toward } \\
\text { the student learning characteristics }\end{array}$ & $90.96 \%$ \\
\hline & $\%\left(\right.$ overlap $\left.1 / W_{X}(:, 2)\right)$ & $\begin{array}{l}\text { The overlap between them toward } \\
\text { their selected supervisors }\end{array}$ & $90.82 \%$ \\
\hline \multirow{2}{*}{$\begin{array}{l}\text { Lecturers' characteristics .vs. their } \\
\text { selected students }\end{array}$} & $\%\left(\right.$ overlap $\left.2 / W_{Y}(:, 1)\right)$ & $\begin{array}{l}\text { The overlap between them toward } \\
\text { the lecturer characteristics }\end{array}$ & $97.07 \%$ \\
\hline & $\%\left(\right.$ overlap $\left.2 / W_{Y}(:, 2)\right)$ & $\begin{array}{l}\text { The overlap between them toward } \\
\text { their selected students }\end{array}$ & $94.40 \%$ \\
\hline \multirow{2}{*}{$\begin{array}{c}\text { Students' learning characteristics .vs. } \\
\text { lecturer characteristics }\end{array}$} & $\%\left(\right.$ overlap $\left.3 / W_{X}(:, 1)\right)$ & $\begin{array}{l}\text { The overlap between them toward } \\
\text { the student learning characteristics }\end{array}$ & $88.13 \%$ \\
\hline & $\%\left(\right.$ overlap $\left.3 / W_{Y}(:, 1)\right)$ & $\begin{array}{l}\text { The overlap between them toward } \\
\text { the lecturer characteristics }\end{array}$ & $75.29 \%$ \\
\hline \multirow{2}{*}{$\begin{array}{l}\text { Selected supervisors' distribution of } \\
\text { students' choice .vs. selected } \\
\text { students's distribution of lecturers' } \\
\text { choice }\end{array}$} & $\%\left(\right.$ overlap $\left.4 / W_{X}(:, 2)\right)$ & $\begin{array}{l}\text { The overlap between them toward } \\
\text { their selected supervisors }\end{array}$ & $92.99 \%$ \\
\hline & $\%\left(\right.$ overlap $\left.4 / W_{Y}(:, 2)\right)$ & $\begin{array}{l}\text { The overlap between them toward } \\
\text { their selected students }\end{array}$ & $77.37 \%$ \\
\hline & & Average of overlap area & $88.38 \%$ \\
\hline
\end{tabular}

Table 13. Measurement of the similarity of the curves

\begin{tabular}{llll}
\hline \multicolumn{2}{c}{ Appropriateness of choice } & \multicolumn{2}{c}{ Characteristics \& Distributions similarity } \\
\hline Corr.coef $\left(W_{X}(:, 1), W_{X}(:, 2)\right)$ & 0.8657 & Corr.coef $\left(W_{X}(:, 1), W_{Y}(:, 1)\right)$ & 0.4064 \\
\hline Corr.coef $\left(W_{Y}(:, 1), W_{Y}(:, 2)\right)$ & 0.9897 & Corr.coef $\left(W_{X}(:, 2), W_{Y}(:, 2)\right)$ & 0.7398 \\
\hline
\end{tabular}

This study's results, such as those presented in Table 12, generally show a significant level of coverage adequacy for all research variables on their existing conditions (88.38\%). Likewise, the correlation test on the appropriateness of choice, both supervisors selected by students (0.8657) and students selected by lecturers (0.9897) showed a very significant degree of similarity. It is also evidenced by the correlation test results on the similarity of distribution between selected supervisors and selected students of 0.7398 .

However, the correlation test for the similarity between student learning characteristics with lecturer characteristics shows different results, below $0.5(0.4064)$. It showed almost no significant correlation between the characteristics of students' learning with lecturers' characteristics as supervisors.

A deeper analysis was performed by observing the visualization shown in Fig. 12 (a). Students with $A K$ and $A$ characteristics were found insufficiently covered under the number of supervisors selected. Students with this condition were $100-90.96=9.04 \%$. Although the percentage is small, the two types of characteristics were not well covered when viewed thoroughly. From Table 9 we can get a comparison between the number of selected supervisors and the number of students for each type of learning characteristic shown in Table 14. That table showed that the most significant portion is taken over by students with characteristics, $V A$, and .

The more in-depth analysis performed in the visualization of Fig. 12 (b) shows that, in general, the lecturers were still considering the appropriateness of the selected students learning characteristics to their characteristics in conducting supervision activities. It has shown by all points of view of overlapping areas 
under the curve above $90 \%$ From Table 10 we can compare the number of selected students and the number of lecturers for each type of character shown in Table 15. The table showed that there were no lecturers classified as having $K$ characteristics. The rest was spread almost evenly, with each lecturer supervising 6-7 students on average, except for $V$ characteristics, which on average, were only four students.

The more in-depth analysis that has been performed in the visualization of Fig. 13 (a) shows a very significant difference between the characteristics of students' learning and the characteristics of lecturers as supervisors. Students' learning characteristics were dominated by $A K$ and , while lecturer characteristics were dominant in $V A$. The behavior of lecturers who still consider the appropriateness of students' supervised learning characteristics with their supervision characteristics raises a very significant difference in distribution, as shown in Fig. 13 (b).

Table 14. Comparison between the number of selected supervisors and the number of students

\begin{tabular}{ccccc}
\hline $\begin{array}{c}\text { Type of } \\
\text { characteristic }\end{array}$ & $\begin{array}{c}\text { Number of students } \\
(\boldsymbol{X}(:, \mathbf{1}))\end{array}$ & $\begin{array}{c}\text { Number of selected supervisors } \\
(\boldsymbol{X}(:, \mathbf{2}))\end{array}$ & $\begin{array}{c}\boldsymbol{X}(:, \mathbf{2}) \\
\boldsymbol{X}(:, \mathbf{1})\end{array}$ & Normalized \\
\hline $1(K)$ & 16 & 10 & 0.6250 & 0.2106 \\
\hline $2(A K)$ & 45 & 20 & 0.4444 & 0.1498 \\
\hline $3(A)$ & 46 & 18 & 0.3913 & 0.1319 \\
\hline $4(V A)$ & 34 & 21 & 0.6176 & 0.2082 \\
\hline $5(V)$ & 9 & 8 & 0.8889 & 0.2996 \\
\hline
\end{tabular}

Table 15. Comparison between the number of selected students and the number of lecturers

\begin{tabular}{ccccc}
\hline $\begin{array}{c}\text { Type of } \\
\text { characteristic }\end{array}$ & $\begin{array}{c}\text { Number of lecturers } \\
(\boldsymbol{Y}(:, \mathbf{1}))\end{array}$ & $\begin{array}{c}\text { Number of selected students } \\
(\boldsymbol{Y}(:, \mathbf{2}))\end{array}$ & $\begin{array}{c}\boldsymbol{Y}(:, \mathbf{2}) \\
\boldsymbol{Y}(:, \mathbf{1})\end{array}$ & Normalized \\
\hline $1(K)$ & 0 & 0 & 0 & 0 \\
\hline $2(A K)$ & 5 & 29 & 5.8000 & 0.2360 \\
\hline $3(A)$ & 6 & 44 & 7.3333 & 0.2984 \\
\hline $4(V A)$ & 9 & 64 & 7.1111 & 0.2893 \\
\hline $5(V)$ & 3 & 13 & 4.3333 & 0.1763 \\
\hline
\end{tabular}
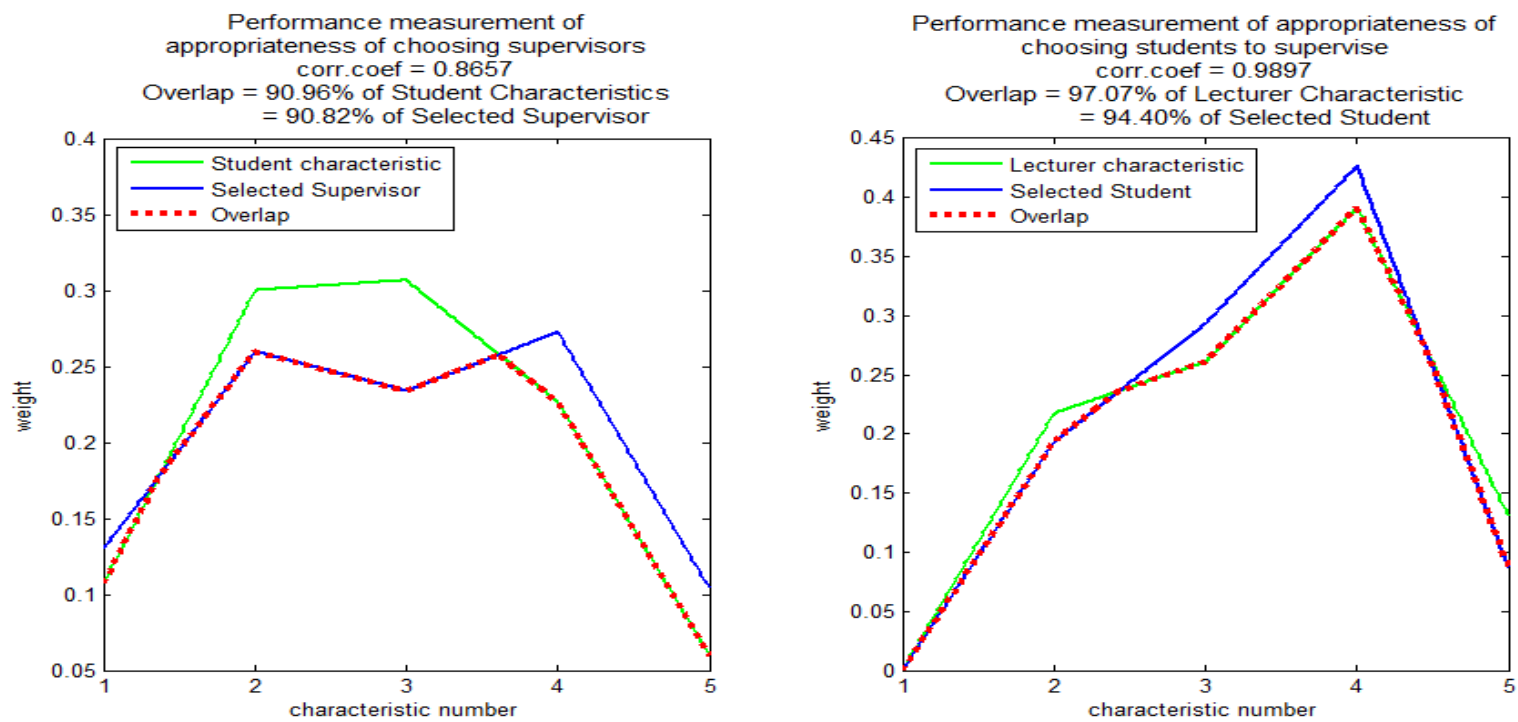

Fig. 12. The results of the measurement of the performance of the relationships between data pairs $\left(W_{X}(:, 1), W_{X}(:, 2)\right)$ and $\left(W_{Y}(:, 1), W_{Y}(:, 2)\right)$ and their visualization 

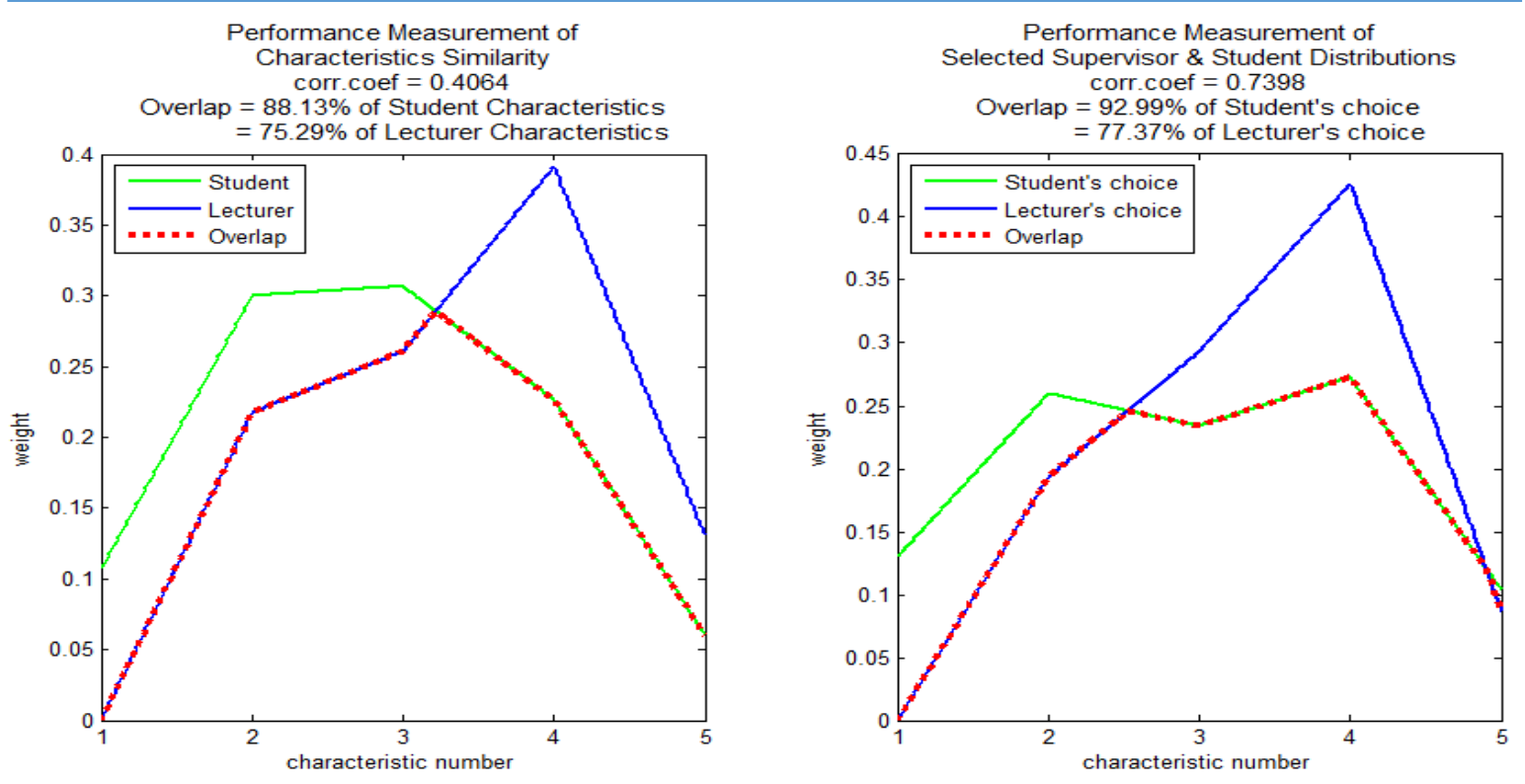

Fig. 13. The results of the measurement of the performance of the relationships between data pairs $\left(W_{X}(:, 1), W_{Y}(:, 1)\right)$ and $\left(W_{X}(:, 2), W_{Y}(:, 2)\right)$ and their visualization

\section{Conclusion}

This study has applied fuzzy-based assessments to build objective perceptions of students' learning characteristics and lecturer characteristics as supervisors through the processing of questionnaires designed in such a way as appropriate for this study's objectives. This study has used the technique of measuring the percentage of overlapping area under the curves and correlation test between a pair of curves as a metric of performance measurement. From the discussion results described previously, some essential points as conclusions are as follows: (1) In general, this study's results indicate a significant level of coverage adequacy for all research variables regarding their existing conditions. It means that the process of the Final Project activities in the Department of Information Technology - Politeknik Negeri Samarinda in 2019 , in terms of students and lecturers' learning characteristics as supervisors and its distributions, was at a reasonable level $(88.38 \%)$; 2) In the correlation test on the appropriateness of choice, both supervisors selected by students (0.8657) and students selected by lecturers $(0.9897)$ showed a very significant degree of similarity, which was correlated with the conclusion at point (1). Correlation tests that have been performed for the similarity between students' and lecturers' learning characteristics as supervisors show almost no significant correlation between them (0.4064). Students' learning characteristics were dominated by $A K$ and $A$ characteristics, while $V A$ characteristics dominate lecturer characteristics. Meanwhile, lecturers were still considering the appropriateness of students' learning characteristics with their characteristics as supervisors in selecting supervised students. It has been demonstrated by all points of view of overlapping areas under curves above $90 \%$. Both results from measurement metrics raise very significant differences in their distribution, both for the supervisor selected by the student and the student selected by the lecturer.

\section{Acknowledgment}

The authors would like to express heartfelt thanks to The Modern Computing Research Center, Politeknik Negeri Samarinda, for giving all their support.

\section{Declarations}

Author contribution. All authors contributed equally to the main contributor to this paper. All authors read and approved the final paper. 
Funding statement. None of the authors have received any funding or grants from any institution or funding body for the research.

Conflict of interest. The authors declare no conflict of interest.

Additional information. No additional information is available for this paper.

\section{References}

[1] A. K. Arslan, "An Exploratory Model of Learning Styles Based on Agent Learning," Adv. High. Educ., vol. 2, no. 2, Apr. 2018, doi: 10.18686/ahe.v2i2.1088.

[2] H. Akram Awla, "Learning Styles and Their Relation to Teaching Styles," Int. J. Lang. Linguist., vol. 2, no. 3, p. 241, 2014, doi: 10.11648/j.jill.20140203.23.

[3] E. Yunanto, A. N. Fatirul, and Harwanto, "The Influence of Problem based Learning, Inquiry, and Learning Style to the Students' Learning Outcomes of Social Science Subject in Junior High School in Indonesia: A Case Study," Int. J. Educ. Res., vol. 7, no. 2, pp. 83-94, 2019, [Online]. Available: Google Scholar.

[4] Z. Lenny, F. Firman, and D. Desyandri, "The effect of using quantum teaching and motivation in learning toward students achievement," J. Apl. IPTEK Indones., vol. 2, no. 3, Jun. 2018, doi: 10.24036/4.32143.

[5] N. Fleming and D. Baume, "Learning Styles Again: VARKing up the right tree!," Educ. Dev., vol. 7, no. 4, p. 4, 2006, [Online]. Available: Google Scholar.

[6] M. Woda and K. Kubacki-Gorwecki, "Students Learning Styles Classification For e-Education," 5th Int. Conf. Inf. Technol. ICIT, 2011, [Online]. Available: Google Scholar.

[7] M. S. Hasibuan, L. E. Nugroho, and P. I. Santosa, "Model E-learning MDP for Learning Style Detection using prior knowledge," Int. J. Eng. Technol, vol. 7, pp. 118-122, 2018, doi: 10.14419/ijet.v7i4.40.24416.

[8] M. S. Hasibuan, L. E. Nugroho, and P. Santosa, "Detecting Learning Style Based on Level of Knowledge," 2018 Third Int. Conf. Informatics Comput., pp. 1-5, Oct. 2018, doi: 10.1109/IAC.2018.8780435.

[9] P. Q. Dung and A. M. Florea, "An approach for detecting learning styles in learning management systems based on learners' behaviours," Int. Conf. Educ. Manag. Innov., vol. 30, pp. 171-177, 2012, [Online]. Available: Google Scholar.

[10] M. S. Hasibuan, L. E. Nugroho, and P. I. Santosa, "Model detecting learning styles with artificial neural network," J. Technol. Sci. Educ., vol. 9, no. 1, p. 85, Feb. 2019, doi: 10.3926/jotse.540.

[11] L. X. Li and S. S. Abdul Rahman, "Students' learning style detection using tree augmented naive Bayes," R. Soc. Open Sci., vol. 5, no. 7, p. 172108, Jul. 2018, doi: 10.1098/rsos.172108.

[12] M. S. Hasibuan and L. Nugroho, "Detecting learning style using hybrid model," 2016 IEEE Conf. e-Learning, eManagement e-Services, pp. 107-111, Oct. 2016, doi: 10.1109/IC3e.2016.8009049.

[13] A. Barman, R. A. Aziz, and Y. M. Yusoff, "Learning style awareness and academic performance of students," SouthEast Asian J. Med. Educ., vol. 8, no. 1, p. 47, Jun. 2014, doi: 10.4038/seajme.v8i1.124.

[14] M. Biabani and S. Izadpanah, "The Study of Relationship between Kolb's Learning Styles, Gender and Learning American Slang by Iranian EFL Students.," Int. J. Instr., vol. 12, no. 2, pp. 517-538, 2019, [Online]. Available: Google Scholar.

[15] H. Awang, N. Abd Samad, N. S. Mohd Faiz, R. Roddin, and J. D. Kankia, "Relationship between the Learning Styles Preferences and Academic Achievement," IOP Conf. Ser. Mater. Sci. Eng., vol. 226, p. 12193, 2017, doi: 10.1088/1757-899x/226/1/012193.

[16] S. Lizote, C. Ribeiro, S. Teston, and J. Werner, "Leaning Styles, Academic Performance and Teaching Evaluation," Rev. Catarinense Da CiÊncia ContÁbil, vol. 18, p. 2837, 2019, [Online]. Available: Google Scholar.

[17] M. M. El Sayed, D. M. Mohsen, R. S. Dogheim, H. H. Zain, and D. Ahmed, "Assessment of Learning Style for Medical Students using VARK Questionnaire," Proc. ISER 30th Int. Conf. Riyadh, Saudi Arab., pp. 28-32, 2016, [Online]. Available: http://www.worldresearchlibrary.org/up_proc/pdf/295-146441517028-32.pdf.

[18] A. B. W. Putra, A. F. O. Gaffar, A. Wajiansyah, and I. H. Qasim, "Feature-Based Video Frame Compression Using Adaptive Fuzzy Inference System," in 2018 International Symposium on Advanced Intelligent Informatics (SAIN), Aug. 2018, pp. 49-55, doi: 10.1109/SAIN.2018.8673386. 
[19] A. Fanany, A. Bramanto, A. Wajiansyah, and S. S., "Texture Feature Extraction based on Local Weighting Pattern (LWP) using Fuzzy Logic Approach," Int. J. Comput. Appl., vol. 179, no. 28, pp. 1-8, Mar. 2018, doi: 10.5120/ijca2018916614. 